\title{
Position of the Society for Nutrition Education and Behavior: Healthful Food for Children is the Same as Adults
}

\author{
Pamela Rothpletz-Puglia, EdD, RD ${ }^{1}$; Lynn Fredericks, $\mathrm{BA}^{2}$; \\ Margaret Rush Dreker, MPA, MLS ${ }^{3}$; Rachael Patusco, DCN, RDN, CSP ${ }^{4}$; \\ Jane Ziegler, DCN, RDN, $\mathrm{LDN}^{5}$
}

\section{INTRODUCTION}

A long-held belief in the US is that children need different types of food than adults do. Now ingrained in American culture, the concept of children's food, or a kids' menu, began more than a century ago when the hospitality, agriculture, and food industries promoted this new social norm to generate revenue. Today, the modern food industry continues to perpetuate demand and explicitly names food for children kids' food as demonstrated by the title of the Global Kids' Food and Beverage Products and Marketing for Preschoolers, Younger Kids, and Tweens ${ }^{1}$ market report. Thus, throughout this position statement, we refer to food for children and youth as kids' food. Unfortunately, these products are often ultraprocessed and high in saturated fat, sodium, and added sugar while providing a narrow range of nutrients. $^{2}$ Moreover, exposure to food-related advertisements and promotion packaging, particularly advertisements related to fast food and sugar-sweetened beverages, is significantly higher in areas with families with low income and racial and ethnic minorities. ${ }^{3-15}$ This exposure encourages diets with limited varieties of healthy options, which can create children's resistance to new food and tastes. ${ }^{6}$ Ultraprocessed food is readily available, further reinforcing unhealthy food preferences, which can persist into later childhood and even adulthood, ultimately increasing lifetime risks of obesity, chronic disease, and other adverse health outcomes. ${ }^{8-11}$ However, nutrition educators can encourage more healthful dietary choices by shifting core beliefs about children's food and educating about how children can eat the same foods as adults. For example, situating the social construct of kids' food within a social ecological context may help identify and leverage modifiable factors to challenge assumptions about the kids' food archetype and improve the overall quality of food for children. In sum, the position of the Society for Nutrition Education and Behavior is that there are no differences between healthful food for children aged 2 and

\footnotetext{
${ }^{1}$ School of Health Professions, Rutgers, The State University of New Jersey, Newark, NJ

${ }^{2}$ Family Cook Productions, New York, NY

${ }^{3}$ Hackensack Meridian School of Medicine, Interprofessional Health Sciences Library, Nutley, NJ

${ }^{4}$ Medical Affairs, GSK Consumer Healthcare, Warren, NJ

${ }^{5}$ Department of Clinical and Preventive Nutrition Sciences, School of Health Professions, Rutgers, The State University of New Jersey, Newark, NJ

Conflict of Interest Disclosure: The authors have not stated any conflicts of interest.

Address for correspondence: Pamela Rothpletz-Puglia, EdD, RD, Associate Professor, School of Health Professions, Rutgers, The State University of New Jersey, Newark, NJ 07107; E-mail: pr.puglia@shp.rutgers.edu

J Nutr Educ Behav. 2022;54:4-11

(C) 2021 Society for Nutrition Education and Behavior. Published by Elsevier Inc. All rights reserved.
}

https://doi.org/10.1016/j.jneb.2021.09.007 older than those for adults, except for age-appropriate adjustments in texture and portion size.

\section{THE ORIGINS OF KIDS' FOOD AS A SOCIAL NORM}

For the purposes of this position statement, kids' food is operationally defined as food likely to be consumed by children aged $2-14$ years, either at home or in the community. The prevailing social construct is that such food is highly processed; energydense; and high in saturated fat, sodium, and added sugar. ${ }^{2}$ A diet favoring these foods can have significant detrimental effects on children's preferences and tastes and may exacerbate food neophobia or picky eating behavior sometime seen in children. ${ }^{12-14}$ To replace this construct with a healthier norm, it is important to understand how the concept of a separate diet for children originated. To that end, social constructionism can illuminate the socioecological etiologies by explaining how behaviors become integrated into everyday social norms. ${ }^{15,16}$

In the US, the concept that food for children is distinct from food for adults has origins in the Volstead Act, enacted in 1919, which prohibited the sale of alcohol. ${ }^{17}$ Before Prohibition, only wealthy families dined at expensive hotel restaurants, as it was considered inappropriate to bring children to a restaurant where alcohol was consumed. ${ }^{2}$ During Prohibition, the hospitality industry attempted to offset lost liquor revenue by expanding their clientele to include children. At the same time, a popular book by pediatrician L. Emmett Holt, The Care and Feeding of Children, recommended a restrictive 
diet for young children, including delaying certain fruits until age 5 and certain meats and vegetables until age 10 , based on the belief that chewing and digestive abilities need to mature. ${ }^{18-20}$ In a 1920 editorial in a restaurant trade magazine, Ethel Maude Colson even suggested a special menu for children. ${ }^{2}$

Toward the end of World War II, pediatrician Benjamin Spock's ${ }^{21}$ book, The Common Sense Book of Baby and Child Care, became the de facto guide for parents. Spock's ${ }^{21}$ infant and child feeding guidelines, which are much less restrictive than those of Holt, ${ }^{20}$ also align more closely with current child feeding recommendations of the American Academy of Pediatrics and the US dietary guidelines. $^{22,23}$ These recommendations include introducing solid food when the child is developmentally ready, usually around 4-6 months, and providing food that is appropriate for the child's oral motor development stage. ${ }^{23}$ Notwithstanding the complex interplay of factors such as parenting style and feeding practices, energy requirements, choking hazards, and taste preferences, by the age of 2 years, most children can eat a diet that is similar to that of adults. $^{22,24,25}$

Yet, kids' food and menus persist, mainly because families are accustomed to them, because restaurants and the food industry in general benefit from marketing to children, and because parents like the low prices. ${ }^{17}$ The concept of kids' food, thus, is a strongly rooted and predominant social norm in US culture. Most people are likely familiar with typical kids' menu items (eg, chicken nuggets or tenders, hamburgers, grilled cheese, french fries, hot dogs, and macaroni and cheese). ${ }^{26,27}$ These types of food are heavily marketed to children in media advertisements including YouTube, packaging, and grocery store promotions; are highly palatable; and are readily available in most US restaurants and grocery markets. ${ }^{5,28-30}$

During the Green Revolution in the 1960s and 1970s, new agricultural technologies led to the development of high-yield crops. Norman Borlaug, the Father of the Green Revolution, received a Nobel Peace Prize in 1970 for his contributions to agricultural advancement, which resulted in substantial production increases and shifts from family farms to agribusiness. ${ }^{31,32}$ Since then, food prices have dropped further: the share of household income spent on food decreased from $17.5 \%$ in 1960 to $6.7 \%$ in 2015, and Americans spend less household income on food than any country in the world. ${ }^{33}$ Today, Americans spend less household income on food than any country in the world. ${ }^{33}$ The low prices and mass production of food, along with technological innovations, have spurred increases in the development and marketing of ultraprocessed food.

Access to and consumption of processed food and sugar-sweetened beverages have increased as low food prices allow supermarkets, food retailers, and fast-food restaurants to offer this food in abundance. ${ }^{34-40}$ Some retailers use opportunistic marketing to draw customers. For example, the first kids' Fun Meal was introduced at Burger Chef in 1973, and the McDonald's Happy Meal debuted in 1978. ${ }^{41}$ In addition, unlike earlier eras when a single pediatrician's book was considered the predominant source of medical information for families, such information now comes from books, social media, and other conflicting sources. Embedded marketing techniques, such as product placements and toy incentives, can be sophisticated, with claims and promises that are difficult to assess. Despite the potential adverse effects of such marketing to kids, the First Amendment of the US Constitution protects it as commercial speech unless deemed deceptive by the Federal Trade Commission. ${ }^{42-44}$ These factors generate a confluence of circumstances that perpetuate harmful social norms and archetypes around the concept of kids' food.

\section{COUNTERING THE KIDS' FOOD ARCHETYPE}

Improving children's diets may require explicating the associated risks and reframing solutions to include community, state, national, and societal involvement in addition to personal behavior. Nutrition educators can address multiple levels of the social ecological model to facilitate healthy adaptation and resilience within the current food environment. ${ }^{45}$ The American food environment has changed dramatically in the past 50 years, and increasing child and adult obesity rates indicate unhealthy societal adaptation to these changes. ${ }^{46}$ By promoting resilience, which is the capacity of a dynamic system to adapt successfully to threats and to harness resources for sustained well-being, these unhealthy adaptations can be redirected. ${ }^{47}$

Unfortunately, as ultraprocessed kids' food becomes more socially accepted, the perceived risks from eating this food weakens such that the risks are not sufficient to promote transformative change. In the field of nutrition education, several models and theories have been used to address these risk perceptions, including self-regulation and motivational theory, the Health Belief Model, and the Health Action Approach Model. ${ }^{48}$ These frameworks can help identify and mitigate risks and ultimately improve children's health. By raising awareness about the health risk of certain food, particularly as they relate to the kids' food archetype, nutrition educators can promote a combination of behavioral and societal solutions to increase individual and community resilience, adaptation, and transformative change. ${ }^{49}$

Many factors determine food choices and nutrition-related behaviors. ${ }^{50}$ The Figure summarizes the framework that nutrition educators can use to identify areas of focus. It includes components from social ecological models based on healthy eating ${ }^{45,50}$ and pediatric-based obesity prevention, ${ }^{51}$ a multisystem model of resilience, ${ }^{52}$ the Cultural Capital Framework, ${ }^{53}$ and an integrative study of developmental competencies in minority children. ${ }^{54}$ Using this framework, nutrition educators can develop interventions directed at building healthy resilience and adaptation to the food environment. This work involves transforming foodrelated norms and behaviors to prioritize accessibility to and preferences 


\begin{tabular}{|c|c|}
\hline Child & $\begin{array}{l}\text { Habit-formed food preferences, knowledge, skills, and beliefs; screen time } \\
\text { and advertising exposure; cultural traditions; self-management, coping, and } \\
\text { resilience; and cooking skills }\end{array}$ \\
\hline Family & $\begin{array}{l}\text { Knowledge; beliefs; coping and resilience; parenting; cohesion; cultural } \\
\text { traditions; risk perceptions; food access; family meals and cooking; lifestyle; } \\
\text { adaptation }\end{array}$ \\
\hline Community & $\begin{array}{l}\text { Food marketing; risk perception; health messaging and inequities; peer and } \\
\text { dominant culture food choices; school meals; food environment (access, } \\
\text { restaurants, grocery, transportation); local norms and campaigns; industry } \\
\text { practices }\end{array}$ \\
\hline $\begin{array}{c}\text { Country: State and } \\
\text { National }\end{array}$ & $\begin{array}{l}\text { National associations; food quality, policies, marketing, and government } \\
\text { funding; media portrayals; social determinants of health inequities; systemic } \\
\text { racism; state and national guidelines }\end{array}$ \\
\hline Cultural & $\begin{array}{c}\text { Cultural humility, inclusivity, and bias; health inequity; corporate } \\
\text { responsibility; gender roles; body image; expectations and norms for eating } \\
\text { out and portion size }\end{array}$ \\
\hline
\end{tabular}

Figure. Framework for nutrition educators to identify modifiable focus areas to counter the kids' food archetype.

for appropriate healthy food at all ages.

A literature search was conducted by a professional librarian using Medline, Cumulative Index of Nursing and Allied Health Literature, and Business Premiere. The search terms included child-oriented food, children's menu, kid's food, kid's menu, children's meals, child nutrition, pediatric obesity, feeding behavior, fast foods, restaurants, marketing, healthy menu, healthy diet, food preferences, and family meals. The focus areas that the authors derived from the main thematic results of the literature review described herein are not exhaustive. However, they do provide example strategies that nutrition educators can use to challenge the current kids' food archetype.

\section{Renaming Kids' Food}

A key first step in the effort to reframe a social norm is to rename it. Over time, societal understandings of issues become more narrowly focused around the most dominant and consistent messaging. ${ }^{55}$ Nutrition educators can widen this focus by avoiding terms such as kids' food or kids' meal in all nutrition-related education materials and replacing them with terms such as moderate plates, moderate portions, or Family Meals. These substitutions can signal positive changes in behaviors and feeding practices. Over time, as the terminology transmits from nutrition educators to parents and the community at large, the social constructs of food behavior also begin to change. ${ }^{15,16}$

\section{Building Cultural Capacity}

Given the rich multicultural traditions and family histories in America, it makes sense to capitalize on existing healthy cultural food practices and traditions while also avoiding subjective norms and unhealthy acculturation practices. ${ }^{53,54,56}$ When using a family-centered approach, health inequities and injustices should be recognized and mitigated. In addition to proximate causes of health, such as diet and physical activity, $^{57-60}$ cultural histories should be respected, and distal causes of health inequity should be considered, such as adverse childhood experiences, trauma, structural racism, ${ }^{61}$ discrimination, socioeconomic status, and lifestyle preferences. Addressing distal causes of health inequity, identifying family strengths, and incorporating healthy cultural legacies may also lead to expanded nutrition education repertoires, shifts in health equity, and increased uptake of inclusive and healthy social norms, including shifting the kids' food archetype. ${ }^{57}$

\section{Promoting Healthy Restaurant Menu Options for Children}

Kids' food is a significant contributor to the US economy and food industry. At non-fast-food outlets, most children order from a children's menu, ${ }^{62}$ whose child-friendly choices have received well-founded criticism from advocacy groups for their poor nutrient quality. In response to this criticism, the industry has attempted to make some public health improvements. ${ }^{63}$ A notable legislative effort is section 4205 of the 2010 Patient Protection and Affordable Care Act, which includes menu labeling laws. In 2011, the National Restaurant Association launched Kids LiveWell, a voluntary program for restaurants that want to include healthier menu choices. The Kids LiveWell criteria stipulates that at least 2 full-serving menu items aimed at kids contain no more than $600 \mathrm{kcal}$ per meal, where $\leq 35 \%$ of the kilocalories are from fat, $\leq 10 \%$ from saturated fat, $\leq 0.05 \%$ from artificial trans-fat, and $\leq 35 \%$ from total sugars, as well as no more than $770 \mathrm{mg}$ sodium and at least 2 food groups. ${ }^{64}$ More recent criteria have been established for side items as the default options, and the 
default options for beverages include water, nonfat or $1 \%$ milk, or $100 \%$ fruit juice. However, it does not appear that US restaurants are fully committed to meeting these guidelines. Studies examining the kilocalorie and macro- and micronutrient content of menu offerings demonstrate that restaurants may offer children's meal combinations that are fewer than 600 kcals, but the macroand micronutrient content have not changed significantly with fat, saturated fat, and sodium exceeding national recommendations. ${ }^{62,65-67}$ Restaurants participating in the Kids LiveWell program have shown no substantial changes in kids' meals across multiple years. ${ }^{62,68}$ One study showed that kids' menu items in the US had fewer kilocalories than kids' menu items in Australia, Canada, New Zealand, Australia, or the United Kingdom. ${ }^{69}$

Several studies have assessed restaurant economic and service trends in kids' meals. In a longitudinal study of menu-ordering patterns among 687,401 children after the initiation of the Kids LiveWell program, the findings showed that children ordered healthier options and that restaurants maintained revenue growth that was consistent with growth before the program was initiated. ${ }^{70}$ Studies aimed at promoting sales of healthful menu items indicate that the restaurant industry is willing to collaborate on public health nutrition initiatives. ${ }^{71-73}$ Nutrition educators can leverage this willingness to promote local and state participation in Kids LiveWell and to advocate that the requirements be expanded to apply to all kids' meals and side dishes rather than just 2 meals on the menu. Considering that sales of sugar-sweetened beverages have increased at chain restaurants in the US, another strategy could include advocating for restaurants to remove soda from children's menus and to include a default non -sugar-sweetened beverage option instead. ${ }^{74-78}$

\section{Promoting Policy and Legislative Solutions}

As fast-food purchases continue to increase, it is important that parents understand the energy and nutrition recommendations for children. ${ }^{79,80}$ Despite the occasional fruit or vegetable offering on a fast-food menu, most items still contain high calories, fat levels, and sodium levels. ${ }^{64,68,81,82}$ In 2018, in accordance with the US Food and Drug Administration Code of Federal Regulations Title 21 101.11, menu labeling laws were enacted for chain restaurants with 20 or more locations. ${ }^{83,84}$ Such policies and legislation affect large numbers of people. Studies examining national pricing, labeling laws, and food marketing strategies show that these policies can promote large-scale positive social and behavior changes. ${ }^{43,81,82}$ Nutrition educators, thus, can use current data to advocate for these changes, but more research is needed to assess the population-level impacts of food labeling on children's menus, as these policies may help identify opportunities for healthier food choices. ${ }^{85,86}$

\section{Creating Mutually Beneficial Consumer Food Options}

Anzman-Frasca et $\mathrm{al}^{87}$ reported that restaurant executives implement menu changes on the basis of profitability, consumer demand, regulation, and corporate social responsibility. Yet, in a hospitality industry study examining children's perceptions of children's menus, Hay $^{88}$ reported that children felt that kids' menus restricted their food choices and regulated entry into the adult world. The author concluded that separate menus for children may therefore become irrelevant or even deterrents in consumers' choices about where to eat and shop. Such evidence provides a rationale for restaurants to include moderate plates or moderate portions vs a children's menu to meet consumer demand. Consumer demand is also increased when parent's perceive restaurant corporate social responsibility, and this perception mediates both healthy eating and willingness to be a customer at a restaurant. ${ }^{89}$ These aims are mutually beneficial.

Still, more work is needed to improve menu options. Nutrition educators can contribute to this effort by collaborating with the food industry to improve perceptions and selections of healthy options. For example, in a study examining 38,343 restaurant menu descriptions, the healthy food was significantly more likely to be described in less appealing ways than unhealthy food on the menu. ${ }^{90}$ For example, engaging words such as crazy, bites, dangerous, and adventure were more likely to describe standard menu items, but words such as simple, mild, plain, fit, and nutritional were more likely to occur on the healthy menu items. ${ }^{5}$ By conducting research, raising awareness, and collaborating with the restaurant industry, nutrition educators can help incorporate more appealing language and advocate for a wider variety of healthy options.

\section{Developing Strategic Health Messaging}

When behavioral outcomes are viewed as personal failures, it results in stigma, such as the blame and lack of empathy associated with human immunodeficiency virus infection, mental illness, substance abuse, and obesity (particularly in adults)..$^{91-93}$ Deeply ingrained values in Western culture, such as independence, free choice, and self-governance, further influence how blame is attributed to individuals. ${ }^{94}$ The media commonly cites individual behavior as causes of poor diet and food choices. ${ }^{95}$ The pervasive and widespread influence of this messaging could be leveraged to mobilize collective efforts aimed at improving social constructs, particularly those related to kids' food. ${ }^{55,94}$ Even more fundamentally, this messaging should frame childhood nutrition as a societal issue in which individuals work with the government, schools, and industry to identify and implement solutions. ${ }^{96,97}$

Nutrition educators can help shape health promotion messaging about kids' meals to include societallevel policy solutions, such as healthy default menu options and menu labeling. They can also promote marketing regulation and work with families to create awareness about advertising and marketing strategies that promote unhealthy food to children. ${ }^{97,98}$ Even children who do not regularly eat processed 
and unhealthy food are regularly exposed to it in the forms of marketing and observations of peers who consume these items. This exposure makes it difficult for most parents to introduce and maintain a healthy variety of minimally processed and whole foods, such as fruits, vegetables, and milk. Nutrition educators can help families recognize that healthy food for children is the same as healthy food for adults. Given the influence of marketing and messaging, there are ample opportunities for nutrition educators to develop strategic and effective health promotion messaging. ${ }^{99}$

\section{Working With Communities and Families}

Building resilience and heathy adaptation to the food environment includes helping families cope with challenges by identifying assets and supportive factors, including responsive feeding practices, family cohesion, positive emotional regulation, and structure. ${ }^{100,101}$ For example, the concept of the Family Meal when families eat together is associated with better diet quality for children and healthy weight maintenance over time. ${ }^{102,103}$ Nutrition educators, thus, can work with busy parents to create sustainable strategies, such as preparing meals in advance. ${ }^{104}$ They can also work with families to reframe concepts of kids' food to exclude ultraprocessed and sugary food and instead incorporate a variety of fruits and vegetables along with adequate water intake. The regular practice of eating a diverse, healthy diet at home could promote better food choices when eating out, which in turn encourages restaurants to include these items in their offerings.

Poverty and household stressors are factors associated with high levels of social vulnerability and low community resilience. Nutrition educators can work within the community to strengthen capacity to limit these adverse effects and overcome challenges. ${ }^{49}$ A first step in this endeavor is connecting cross-sector partnerships to address nutrition problems in different domains of the social ecological model (Figure). Creating strategically coordinated services that address social determinants of health, such as reframing the social construct of kids' food, requires situating interventions within the context of the community and family using a transgenerational, lifestylebased approach. ${ }^{49,104}$ For example, in immigrant families, young children may develop preferences for food served in school rather than the cultural foods served at home. In response, parents may begin to prepare separate meals for their children and to think of their culturally traditional foods as for adults only, thus perpetuating the kids' food archetype. Nutrition educators can intervene here and work with the family and school to honor healthy cultural food practices. This population-based health approach to nutrition practice involves understanding the family and community context and developing community partnerships to create social change. ${ }^{49}$

\section{CONCLUSION}

Nutrition educators play key roles in shifting consumer demand and cultural norms about food choices. As such, they can help improve the unhealthy aspects of the kids' food archetype. By shifting norms about kids' food toward healthy food that both adults and children can enjoy (while accounting for age-appropriate and nutrition requirements), nutrition educators can promote healthy social and behavior changes at the individual, family, and community levels. Specific areas of focus explicitly renaming kids' meal items as moderate plates, family meals, or moderate portions; building cultural capacity around healthful food for children; collaborating with policy makers and the restaurant industry to promote and conduct research on healthy menu options and improve menu labeling; promoting mutually beneficial relationships between food consumers and the industries that serve them; developing strategic health promotion messaging; and working with families and communities to reframe the kids' food archetype. By recognizing the challenges of the current food environment and by partnering with governments, legislators, schools, and industries to address these challenges, nutrition education can play an integral role in decreasing lifetime risks of obesity, chronic disease, and other adverse health outcomes related to diet and food choices.

\section{REFERENCES}

1. HTF Market Intelligence. Global kids food and beverage market research report 2019 - market size, share, price, trend and forecast. https://www. htfmarketreport.com/enquiry-beforebuy/2407311-global-kids-food-andbeverages-market-5. Accessed August 18, 2021.

2. Siegel BE. Kid Food: the Challenge of Feeding Children in a Highly Processed World. Oxford University Press; 2019.

3. Powell LM, Wada R, Kumanyika SK. Racial/ethnic and income disparities in child and adolescent exposure to food and beverage television ads across the US media markets. Health Place. 2014;29:124-131.

4. Fleming-Milici F, Harris JL. Television food advertising viewed by preschoolers, children and adolescents: contributors to differences in exposure for black and white youth in the United States. Pediatr Obes. 2018;13:103-110.

5. Elliott C. 'Big Food' and 'gamified' products: promotion, packaging, and the promise of fun. Crit Public Health. 2015;25:348-360.

6. Alfaro B, Rios Y, Arranz S, Varela P. Understanding children's healthiness and hedonic perception of school meals via structured sorting. Appetite. 2020;144:104466.

7. Monteiro CA, Moubarac JC, Cannon G, Ng SW, Popkin B. Ultra-processed products are becoming dominant in the global food system. Obes Rev. 2013;14(suppl 2):21-28.

8. Nicklaus S, Boggio V, Chabanet C, Issanchou S. A prospective study of food variety seeking in childhood, adolescence and early adult life. Appetite. 2005;44:289-297.

9. Skinner JD, Carruth BR, Bounds W, Ziegler P, Reidy K. Do food-related experiences in the first 2 years of life predict dietary variety in school-aged children? J Nutr Educ Behav. 2002;34:310-315.

10. Devine CM, Connors M, Bisogni CA, Sobal J. Life-course influences on fruit and vegetable trajectories: 
qualitative analysis of food choices. $J$ Nutr Educ. 1998;30:361-370.

11. Yan Y, Zheng W, Ma Q, et al. Childto-adult body mass index trajectories and the risk of subclinical renal damage in middle age. Int $J$ Obes (Lond). 2021;45:1095-1104.

12. Hastings G, McDermott L, Angus K, Stead M, Thomson S. The Extent, Nature, and Effects of Food Promotion to Children: A Review of the Evidence - Technical Paper Prepared for the World Health Organization. World Health Organization; 2006. http://apps.who.int/iris/bitstream/handle/10665/43627/ 9789241595247_eng.pdf. Accessed August 18, 2021.

13. Smith R, Kelly B, Yeatman H, Boyland E. Food marketing influences children's attitudes, preferences and consumption: a systematic critical review. Nutrients. 2019;11:875.

14. Lafraire J, Rioux C, Giboreau A, Picard D. Food rejections in children: cognitive and social/environmental factors involved in food neophobia and picky/fussy eating behavior. Appetite. 2016;96:347-357.

15. Conrad P, Barker KK. The social construction of illness: key insights and policy implications. J Health Soc Behav. 2010;51(suppl):S67-S79.

16. Goffman E. Frame Analysis: An Essay on the Organization of Experience. Harvard University Press; 1974.

17. Kelly K. The Volstead Act. US National Archives. https://www.archives.gov/education/lessons/volstead-act. Accessed April 28, 2018.

18. Humes M. Feeding the kiddie: a brief history of the children's menu. Slate. http://www.slate.com/articles/life/ food/2013/08/children_s_menu_history_how_prohibition_and_emmett_holt_gave_rise_to_kid.html. Accessed May 16, 2017.

19. Haley AP. Dining in high chairs: children and the American restaurant industry, 1900-1950. Food Hist. 2009; 7:69-94.

20. Holt LE. The Care and Feeding of Children: A Catechism for the Use of Mothers and Children's Nurses. D. Appelton and Company; 1907.

21. Spock B. The Common Sense Book of Baby and Child Care. Meredith Press; 1946.

22. U.S. Department of Agriculture and U.S. Department of Health and Human Services. Dietary Guidelines for Americans, 2020-2025. 9th Ed. 2020.
23. American Academy of Pediatrics. Bright Futures: Guidelines for Health Supervision of Infants, Children, and Adolescents. 4th ed. American Academy of Pediatrics; 2017.

24. Birch LL, Doub AE. Learning to eat: birth to age 2 y. Am J Clin Nutr. 2014; $99: 723 s-728$ s.

25. Riley LK, Rupert J, Boucher O. Nutrition in toddlers. Am Fam Physician. 2018;98:227-233.

26. Eissa MA, Hearne K, Saavedra N. Comparison of children's menu items at full- and quick-service restaurants. South Med J. 2018;111:192-197.

27. DuBreck CM, Sadler RC, Arku G, Seabrook J, Gilliland J. A comparative analysis of the restaurant consumer food environment in Rochester (NY, USA) and London (ON, Canada): assessing children's menus by neighbourhood socio-economic characteristics. Public Health Nutr. 2019;22: 1654-1666.

28. Tan L, Ng SH, Omar A, Karupaiah T. What's on YouTube? A case study on food and beverage advertising in videos targeted at children on social media. Child Obes. 2018;14:280-290.

29. Elliott C. Tracking kids' food: comparing the nutritional value and marketing appeals of child-targeted supermarket products over time. $\mathrm{Nu}$ trients. 2019;11:1850.

30. Harris JL, LoDolce M, Dembek C, Schwartz MB. Sweet promises: candy advertising to children and implications for industry self-regulation. Appetite. 2015;95:585-592.

31. Conway G. The Doubly Green Revolution: Food for All in the Twenty-First Century. Comstock Pub; 1998.

32. Paarlberg R. Food Politics. Oxford University Press; 2013.

33. World Economic Forum. Which countries spend the most on food? This map will show you. 2015. https://www.weforum.org/agenda/ 2016/12/this-map-shows-how-mucheach-country-spends-on-food/. Accessed November 12, 2021.

34. James P, Seward MW, James O'Malley A, Subramanian SV, Block JP. Changes in the food environment over time: examining 40 years of data in the Framingham Heart Study. Int J Behav Nutr Phys Act. 2017;14:84.

35. Piernas C, Popkin BM. Increased portion sizes from energy-dense foods affect total energy intake at eating occasions in US children and adolescents: patterns and trends by age group and sociodemographic characteristics, 1977-2006. Am J Clin Nutr. 2011;94:1324-1332.

36. Nielsen SJ. Popkin BM. Patterns and trends in food portion sizes, 1977 -1998. JAMA. 2003;289:450-453.

37. Lin B, GJ, Frazao E. Away-From-Home Foods Increasingly Important to Quality of American Diet. US Department of Agriculture Economic Research Service; 1999.

38. Almeida J, Duncan DT, Sonneville KR. Obesogenic behaviors among adolescents: the role of generation and time in the United States. Ethn Dis. 2015;25:58-64.

39. Powell LM, Nguyen BT. Fast-food and full-service restaurant consumption among children and adolescents: effect on energy, beverage, and nutrient intake. JAMA Pediatr. 2013;167:14-20.

40. Bhutani S, Schoeller DA, Walsh MC, McWilliams C. Frequency of eating out at both fast-food and sit-down restaurants was associated with high body mass index in non-large metropolitan communities in midwest. Am J Health Promot. 2018;32:75-83.

41. Spartos C. MC in a Box: scarfing down 30 years of happy meals. New York Post. 2009.

42. Federal Trade Commission. A Review of Food Marketing to Children and Adolescents: A Follow-Up Report. Federal Trade Commission; 2012.

43. Sonneville KR, Long MW, Ward ZJ, et al. BMI and healthcare cost impact of eliminating tax subsidy for advertising unhealthy food to youth. Am J Prev Med. 2015;49:124-134.

44. Burd G. Fast food, families and advertising as a cultural site. J Mass Communicat Journalism. 2018;8:362.

45. Story M, Kaphingst KM, RobinsonO’Brien R, Glanz K. Creating healthy food and eating environments: policy and environmental approaches. Annu Rev Public Health. 2008;29:253-272.

46. Zhang Y, Yang J, Hou W, Arcan C. Obesity trends and associations with types of physical activity and sedentary behavior in US adults: National Health and Nutrition Examination Survey, 2007-2016. Obesity (Silver Spring). 2021;29:240-250.

47. Southwick SM, Bonanno GA, Masten AS, Panter-Brick C, Yehuda R. Resilience definitions, theory, and challenges: interdisciplinary perspectives. Eur J Psychotraumatol. 2014;5:10. 
48. Contento I. Foundation in Theory and Research: Increasing Awareness and Enhancing Motivation. Nutrition Education: Linking Research, Theory, and Practice. 1 ed. Jones and Bartlett; 2007.

49. Ellis WR, Dietz WH. A new framework for addressing adverse childhood and community experiences: the building community resilience model. Acad Pediatr. 2017;17:S86-S93.

50. Contento IR. Nutrition Education: Linking Research, Theory, and Practice. Jones and Bartlett Publishers; 2015.

51. Harrison K, Bost KK, McBride BA, et al. Toward a developmental conceptualization of contributors to overweight and obesity in childhood: the six-Cs model. Child Dev Perspect. 2011;5:50-58.

52. Liu JJW, Reed M, Girard TA. Advancing resilience: an integrative, multi-system model of resilience. Pers Individ Dif. 2017;111:111-118.

53. Cuy Castellanos D, Miller ME. Exploration of sugar-sweetened beverage intake in a Latinx population. $J$ Nutr Educ Behav. 2020;52:281-289.

54. García Coll C, Lamberty G, Jenkins $\mathrm{R}$, et al. An integrative model for the study of developmental competencies in minority children. Child Dev. 1996;67:1891-1914.

55. Foley K, Ward P, McNaughton D. Innovating qualitative framing analysis for purposes of media analysis within public health inquiry. Qual Health Res. 2019;29:1810-1822.

56. Kaplan SG, Arnold EM, Irby MB, Boles KA, Skelton JA. Family systems theory and obesity treatment: applications for clinicians. Infant Child Adolesc Nutr. 2014;6:24-29.

57. Ranjbar N, Erb M, Mohammad O, Moreno FA. Trauma-informed care and cultural humility in the mental health care of people from minoritzed communities focus. Am Psychiatr Publ. 2020;18:8-15.

58. Felitti VJ. Origins of the ACE study. Am J Prev Med. 2019;56:787789.

59. Sallis JF, Saelens BE, Frank LD, et al. Neighborhood built environment and income: examining multiple health outcomes. Soc Sci Med. 2009;68:12851293.

60. Cronholm PF, Forke CM, Wade R, et al. Adverse childhood experiences: expanding the concept of adversity. Am J Prev Med. 2015;49:354-361.
61. Bailey ZD, Krieger N, Agénor M, Graves J, Linos N, Bassett MT. Structural racism and health inequities in the USA: evidence and interventions. Lancet. 2017;389:1453-1463.

62. Wolfson JA, Moran AJ, Jarlenski MP, Bleich SN. Trends in Sodium Content of Menu Items in Large Chain Restaurants in the U.S. American. Am J Prev Med. 2018;54:28-36.

63. Kraak V, Englund T, Misyak S, Serrano E. Progress evaluation for the restaurant industry assessed by a voluntary marketing-mix and choicearchitecture framework that offers strategies to nudge American customers toward healthy food environments, 2006-2017. Int J Environ Res Public Health. 2017:14.

64. National Restaurant Association. National Restaurant Association Launches Kids LiveWell 2.0. https:// restaurant.org/research-and-media/ media/press-releases/national-restaurant-association-launches-kids-livewell2/. Accessed November 12, 2021.

65. Deierlein AL, Peat K, Claudio L. Comparison of the nutrient content of children's menu items at US restaurant chains, 2010-2014. Nutr J. 2015;14:80.

66. Hill JL, Olive NC, Waters CN, Estabrooks PA, You W, Zoellner JM. Lack of healthy food options on children's menus of restaurants in the health-disparate Dan River region of Virginia and North Carolina, 2013. Prev Chronic Dis. 2015;12:E40.

67. Sliwa S, Anzman-Frasca S, Lynskey V, Washburn K, Economos C. Assessing the availability of healthier children's meals at leading quick-service and full-service restaurants. J Nutr Educ Behav. 2016;48. 242-9.e1.

68. Moran AJ, Block JP, Goshev SG, Bleich SN, Roberto CA. Trends in nutrient content of children's menu items in US Chain restaurants. $A m \mathrm{~J}$ Prev Med. 2017;52:284-291.

69. Hobin E, White C, Li Y, Chiu M, O'Brien MF, Hammond D. Nutritional quality of food items on fastfood 'kids' menus': comparisons across countries and companies. Public Health Nutr. 2014;17:2263-2269.

70. Ayala GX, Castro IA, Pickrel JL, et al. A cluster randomized trial to promote healthy menu items for children: the kids' choice restaurant program. Int $J$ Environ Res Public Health. 2017;14: 1494.
71. Ayala GX, Castro IA, Pickrel JL, et al. A restaurant-based intervention to promote sales of healthy children's menu items: the Kids' Choice Restaurant Program cluster randomized trial. BMC Public Health. 2016;16:250.

72. Ferrante MJ, Johnson SL, Miller J, Moding KJ, Bellows LL. Does a vegetable-first, optimal default strategy improve children's vegetable intake? A restaurant-based study. Food Qual Preference. 2019;74:112-117.

73. Frelier JM, Moran AJ, Vercammen KA, Jarlenski MP. Bleich SN. Trends in calories and nutrients of beverages in US chain restaurants, 2012-2017. Am J Prev Med. 2019;57: 231-240

74. Moran AJ, Subramanian SV, Rimm EB, Bleich SN. Characteristics associated with household purchases of sugar-sweetened beverages in US restaurants. Obesity (Silver Spring). 2019;27:339-348.

75. Mueller MP, Wilde P, Folta SC, Anzman-Frasca S, Economos CD. Availability of healthier children's menu items in the top selling quick service restaurant chains (2004-2015). Am J Public Health. 2019;109:267-269.

76. Ribakove S, Wootan MG. Soda Still on the Menu. Center for the Science of Public Interest; 2019.

77. Yang YT, Benjamin-Neelon SE. Recent progress in children's meals law in restaurants in Baltimore City and California State: making a healthy beverage option the default choice. Prev Med. 2019;123:160-162.

78. Lynskey VM, Anzman-Frasca S, Harelick L, et al. Low parental awareness about energy (calorie) recommendations for children's restaurant meals: findings from a national survey in the USA. Public Health Nutr. 2017;20:1921-1927.

79. Harris JL, Hyary M, CY SN. Rudd Report: Parents' Reports of Fast-Food Purchases for Their Children: Have They Improved? University of Connecticut; 2018.

80. Soo J, Harris JL, Davison KK, Williams DR, Roberto CA. Changes in the nutritional quality of fast-food items marketed at restaurants, $2010 \mathrm{v}$. Public Health Nutr. 2013;2018:1-11.

81. Bleich SN, Moran AJ, Jarlenski MP, Wolfson JA. Higher-calorie menu items eliminated in large chain restaurants. Am J Prev Med. 2018;54:214220. 
82. Uniform Compliance Date for Food Labeling Regulations. 21 CFR §101; 2021. https://www.federalregister.gov/ documents/2021/01/06/2020-29273/ uniform-compliance-date-for-foodlabeling-regulations. Accessed November 2, 2021.

83. Alexander E, Rutkow L, Gudzune KA, Cohen JE, McGinty EE. Healthiness of US chain restaurant meals in 2017. J Acad Nutr Diet. 2020;120:1359-1367.

84. Long MW, Gortmaker SL, Ward ZJ, et al. Cost Effectiveness of a SugarSweetened Beverage Excise Tax in the U.S. American. Am J Prev Med. 2015;49:112-123.

85. Crockett RA, King SE, Marteau TM, et al. Nutritional labelling for healthier food or non-alcoholic drink purchasing and consumption. Cochrane Database Syst Rev. 2018;2: CD009315.

86. Anzman-Frasca S, Folta SC, Glenn ME, et al. Healthier children's meals in restaurants: an exploratory study to inform approaches that are acceptable across stakeholders. J Nutr Educ Behav. 2017;49:285-295.e1.

87. Hay B. Why do kids' menus always have chicken nuggets?': children's observations on the provision of food in hotels on family holidays. Hosp Soc. 2018;8:69-96.

88. Lee K, Conklin M, Bordi P, Cranage D. Restaurants' healthy eating initiatives for children increase parents' perceptions of CSR, empowerment, and visit intentions. Int $J$ Hosp Manag. 2016;59:60-71.

89. Turnwald BP, Jurafsky D, Conner A, Crum AJ. Reading between the menu lines: are restaurants' descriptions of "healthy" foods unappealing? Health
Psychol Off J Div Health Psychol Am Psychol Assoc. 2017;36:1034-1037.

90. Grossman CI, Stangl AL. Editorial: Global action to reduce HIV stigma and discrimination. J Int AIDS Soc. 2013;16(suppl 2):18881.

91. Pescosolido BA, Martin JK. The stigma complex. Annu Rev Sociol. 2015;41:87-116.

92. Hatzenbuehler ML, Phelan JC, Link BG. Stigma as a fundamental cause of population health inequalities. $A m \mathrm{~J}$ Public Health. 2013;103:813-821.

93. Sun Y, Krakow M, John KK, Liu M, Weaver J. Framing obesity: how news frames shape attributions and behavioral responses. J Health Commun. 2016;21:139-147.

94. Kim SH, Willis LA. Talking about obesity: news framing of who is responsible for causing and fixing the problem. J Health Commun. 2007; 12:359-376.

95. Barry CL, Gollust SE, Niederdeppe J. Are Americans ready to solve the weight of the nation? $N$ Engl J Med. 2012;367:389-391.

96. Smith R, Kelly B, Yeatman H, et al. Advertising placement in digital game design influences children's choices of advertised snacks: a randomized trial. $J$ Acad Nutr Diet. 2020;120:404-413.

97. Prowse RJL, Naylor PJ, Olstad DL, et al. Impact of a capacity-building intervention on food marketing features in recreation facilities. $J$ Nutr Educ Behav. 2020;52:935-943.

98. Ray C, Campbell K, Hesketh KD. Key messages in an early childhood obesity prevention intervention: Are they recalled and do they impact children's behaviour? Int J Environ Res Public Health. 2019;16:1550.
99. Sigman-Grant M, Hayes J, VanBrackle A, Fiese B. Family resiliency: a neglected perspective in addressing obesity in young children. Child Obes. 2015;11:664-673.

100. Skouteris H, Bergmeier HJ, Berns $\mathrm{SD}$, et al. Reframing the early childhood obesity prevention narrative through an equitable nurturing approach. Matern Child Nutr. 2021;17:e13094.

101. Fulkerson JA, Larson N, Horning M, Neumark-Sztainer D. A review of associations between family or shared meal frequency and dietary and weight status outcomes across the lifespan. J Nutr Educ Behav. 2014:46:2-19.

102. Utter J, Larson N, Berge JM, Eisenberg ME, Fulkerson JA, NeumarkSztainer D. Family meals among parents: associations with nutritional, social and emotional wellbeing. Prev Med. 2018;113:7-12.

103. Larson N, Fulkerson JA, Berge JM, Eisenberg ME, Neumark-Sztainer D. Do parents perceive that organized activities interfere with family meals? Associations between parent perceptions and aspects of the household eating environment. $J$ Acad Nutr Diet. 2020;120:414-423.

104. Ford DE. The community and public well-being model: a new framework and graduate curriculum for addressing adverse childhood experiences. Acad Pediatr. 2017;17:S9-S11.

\section{ORCID}

Pamela Rothpletz-Puglia: http:// orcid.org/0000-0003-3112-0921 